\title{
Characterization of cement composites based on recycled cellulosic waste paper fibres
}

https://doi.org/10.1515/eng-2018-0046

Received November 9, 2017; accepted March 8, 2018

\begin{abstract}
Nowadays, there is paying an attention to the utilization of natural, renewable and biodegradable resources of raw materials of lignocellulosic character, residues from agricultural crops and wood processing as well as waste from papermaking industry in building composite materials preparing. Also recycled fibres coming from waste paper are considered as valuable material. The objective of this study is to utilize these recycled cellulosic fibres into cement composites and characterise their impact on resulting physical and mechanical properties of fresh and hardened cement composites. Manufactured cement composites contained $0.2 \%, 0.3 \%$ and $0.5 \%$ addition of cellulosic fibres. In fresh fibre cement mixtures reduction in workability with increasing amount of cellulose fibres was noticed. Density as well as compressive and flexural strength of 28 and 90 days hardened fibre cement composites was tested. Distribution of cellulosic fibres with $0.5 \%$ addition in hardened fibre cement composites was also observed. The results of density determination of 28 and 90 days hardened fibre cement composites showed reduction in their values related to weight lighter concretes. Compressive strengths of fibre cement composites have shown decreasing character with increasing added amount of cellulosic fibres into the mixture up to $0.5 \%$. Maximal decrease in compressive strength values was observed in composites containing $0.5 \%$ of cellulosic fibres. However, obtained strength parameter values of hardened composites had satisfying results for their application in construction as non-load bearing building material.
\end{abstract}

Keywords: fibre cement composite, recycled waste paper, cellulosic fibre

\footnotetext{
*Corresponding Author: Nadezda Stevulova: Institute of Environmental Engneering, Faculty of Civil Engineering, Technical University of Košice, Košice, 04200, Slovakia,

E-mail: nadezda.stevulova@tuke.sk

Viola Hospodarova: Institute of Environmental Engineering, Faculty of Civil Engineering, Technical University of Košice, Košice, 04200, Slovakia
}

\section{Introduction}

The ecological value of engineered structures reinforced by synthetic fibres can be enhanced by their replacement with natural and vegetable fibres [1, 2]. In last years, ligno/cellulosic fibres are used as reinforcing/filler material in inorganic or organic matrix not only in construction industry. A great attention is paid to the development of concretes with reduced environmental footprint. Cement composites incorporating cellulosic fibres, so-called "green" concretes, belong to eco-friendly engineering materials with reduced carbon footprint compared Portland cement based concrete [3]. Natural fibres/aggregates obtained from the residual peels, leaves, stems and pulp of plants, wood, agricultural and industrial waste such as flax, sugarcane, pineapple, banana, coconut, sisal, jute, and hemp hurds are an easily available all over the world, they are considered as a cheap and fast renewable source with carbon oxide sequestration [4]. Composite materials manufactured using natural fibres have indicated better technical and economic feasibility to similar materials that were prepared with synthetic fibres [5-8]. Addition of reinforcing cellulosic fibres coming from different natural sources can improve properties of composites based on cement binder: to reduce the density, to increase the flexural strength of concrete [9-11], to control of the initiation and growth of microcracks [12], and to improve the impact resistance [13]. The application of waste and natural cellulosic fibres into cement based composites has huge potential in building construction [14] but also in different industrial sectors [15]. The development of bio-composites by using recycled cellulosic fibres from waste paper is currently at the centre of attention. The recycled waste cellulosic fibres are considered as a suitable alternative for convenient fibres [16]. However, the end quality of the recycled fibres is determined by the properties of used waste types of paper [14]. Afore mentioned cellulosic fibres offer

\footnotetext{
Vojtech Vaclavik, Tomas Dvorsky, Tomas Danek: Department of Environmental Engineering, Faculty of Mining and Geology, VSBTechnical University of Ostrava, Ostrava-Poruba,70800, Czech Republic
} 
effective way of their utilization as reinforcing element of cement composites and play significant role in sustainable development of building materials [17].

The aim of this work is to utilize three types recycled cellulosic fibres originating from waste paper to the cement mixture and to determine the influence of their 0.2 $0.5 \%$ addition on flow behaviour of fresh fibre cement mixture and on density and mechanical properties (compressive and flexural strength) of 28 and 90 days hardened fibre cement composites.

\section{Materials and methods}

\subsection{Materials}

In this experimental work, three types of unbleached cellulosic fibres (Fig. 1) originating from recycled waste paper were used for preparation of fibre cement composites. They were applied as $0.2 \%, 0.3 \%$ and $0.5 \%$ addition into the cement mixtures.

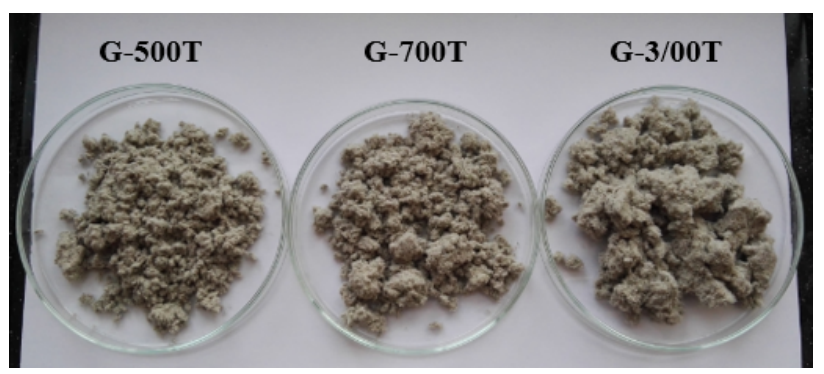

Figure 1: Recycled cellulosic waste paper fibres (grey colour)

Recycled cellulosic waste paper fibres are characterized in Table 1.

Ordinary Portland cement type CEM I 42.5 N was used as binding agent. Fibre cement specimens were manufactured using standard silica sand in accordance with European standard STN EN 196-1 [18]. Tap water was used for preparation of fibre cement composites.

\subsection{Preparation of specimens}

The cement mixture has been designed from standard silica sand (1350 $\pm 5 \mathrm{~g})$, cement $(450 \pm 2 \mathrm{~g})$ and water (250 $\pm 1 \mathrm{~g})$ having water-to-cement ratio $(\mathrm{w} / \mathrm{c})=0.55$. Recycled waste paper fibres were used as $0.2,0.3$ and $0.5 \mathrm{wt} . \%$ addition from filler and binder weight. Control cement sample was also prepared without using cellulosic fibres. For the production and characterization of the composites, prisms with dimensions $40 \times 40 \times 160 \mathrm{~mm}$ were moulded. The preparation of fresh mixtures started with soaking of cellulosic fibres in approximately with half volume of water by manual mixing. Remaining amount of water, cement and sand was added, and mixture was mechanically stirred to allow the homogenous distribution of cellulosic fibres in cement mixture. The fresh mixture was pour into the standard steel moulds and consolidated by a jolting apparatus. After $24 \mathrm{~h}$, specimens were removed from the moulds and placed into the water bath to cure under laboratory condition $+20^{\circ} \mathrm{C}$ for 28 and 90 days. After complete hardening, testing the density and mechanical properties of 28 and 90 days cured samples was carried out. Three specimens were taken for each type of fibre cement composites.

\subsection{Methods of optical, physical and mechanical testing}

Optical analysis focusing on pores and fibres distribution in the hardened composites was performed in reflected UV light on cut fibre cement samples by Olympus BX60 polarizing microscope with Jenoptik ProgRes CFscan digital camera and NIS-Elements image analysis software. The observation in UV light with WU filter was used to distinguish paper fibres (blue fluorescent colour) from inorganic matrix (no fluorescence). Flow behaviour of the freshly prepared cement mixtures with cellulosic fibres (indicating their workability) was estimated by a flow table test in accordance with European standard STN EN 1015-3 [18]. The density of fibre cement composites after 28 and 90 days of curing was determined. Determination of compressive strength of 28 and 90 days hardened composites was carried out by compression testing machine FORM+TEST with using a loading rate $2400 \pm 200 \mathrm{~N} / \mathrm{s}$ in compliance with European standard STN EN 196-1 [19]. Three point bending test was used for determination of flexural strength on the previously mentioned testing machine with a loading rate $50 \pm 10 \mathrm{~N} / \mathrm{s}$.

\section{Results and discussion}

\subsection{Optical analysis}

Optical microscopy is one of an excellent technique providing examination of surface morphology of fibre cement composites. Photomicrographs (Fig. 2) show micro texture of 28 days of hardened cement composites samples con- 
Table 1: Selected properties of recycled wastepaper fibres

\begin{tabular}{lllllll}
\hline $\begin{array}{l}\text { Waste paper } \\
\text { fibre }\end{array}$ & $\begin{array}{l}\text { Cellulose } \\
\text { content }[\%]\end{array}$ & $\begin{array}{l}\text { Bulk density } \\
{\left[\mathrm{kg} / \mathrm{m}^{3}\right]}\end{array}$ & $\begin{array}{l}\text { Max. length } \\
{[\mu \mathrm{m}]}\end{array}$ & $\begin{array}{l}\text { Dry matter } \\
{[\%]}\end{array}$ & $\begin{array}{l}\text { Ash } \\
{[\%]}\end{array}$ & $\begin{array}{l}\text { Thermal } \\
\text { conductivity } \\
{[\mathrm{W} / \mathrm{m} . \mathrm{K}]}\end{array}$ \\
\hline G-500T & 80 & $50-100$ & 400 & 93 & 20 & 0.0634 \\
G-700T & 80 & $40-70$ & 600 & 93 & 20 & 0.0599 \\
G-3/00T & 80 & $30-50$ & 1200 & 93 & 20 & 0.0595 \\
\hline
\end{tabular}

taining recycled cellulosic fibres (G-500T, G-700T and G3/00T). The differences in morphology are dependent upon the type of the used fibre. The pores are homogeneously distributed in the matrix and only occasionally small agglomerates and clusters are observed. The pores size is from tenth of millimetres to millimetres. They are mostly of the spherical shape. Minor amount of pores is of irregular, slightly elongated shape. In some cases, pores can be filled with fibre clusters.
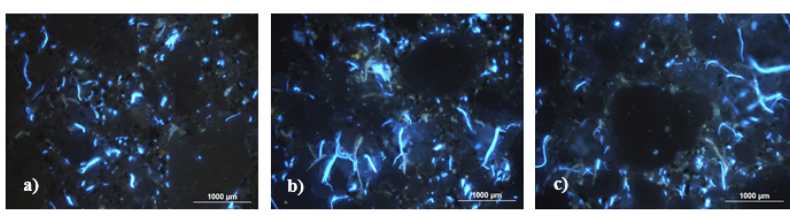

Figure 2: Photomicrographs of 28 days hardened fibre cement composite texture in the UV light with WU filter a) G-500T $0.5 \%$ b) G700T $0.5 \%$ c) G-3/00T $0.5 \%$

\subsection{Flow behaviour}

The set of fresh fibre cement mixtures and mixture without cellulosic fibres was prepared by using the same amount of cement, sand, water as well. The effect of fibre addition in portion $0.2 \%, 0.3 \%$ and $0.5 \%$ was investigated. As shown in Fig. 3, the flow table value of cellulosic fibre cement composites containing recycled waste paper fibres decreases with increasing quantity of fibres up to $0.5 \%$. Cellulosic fibres have hydrophilic nature and this characteristic caused that fibres retain water, swell and fresh fibre cement mixture become less fluid and more compact with rising amount of cellulosic fibres up. This influence of cellulosic fibres on flowability of fresh cement mixture was also observed in [20, 21].

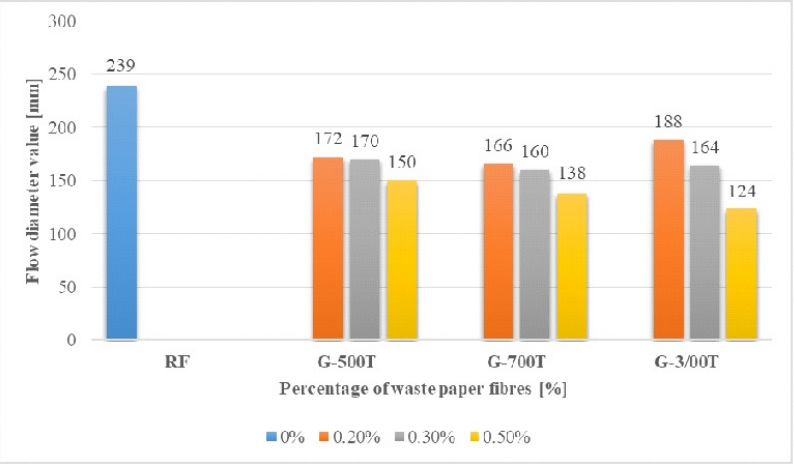

Figure 3: Flow diameter values of cement composites with waste paper fibres

\subsection{Density and mechanical properties}

Table 2 summarises resulting values of density and compressive and flexural strength of prepared fibre cement composites after 28 and 90 days of hardening in comparison to reference samples. Cellulosic paper fibres have low densities and increasing amount of cellulosic fibres in the mixture influences the density of composites with fibres [22]. Maximal decrease in density was observed up to $9 \%$.

Results of mechanical properties of fibre cement composites showed that they are a function of fibre content in the mixture. It is apparent that higher concentration of used fibres led to lower values of compressive and flexural strength in comparison with reference sample. As it can be seen from Table 2, decrease in the compressive strength parameter of cement composites based on waste paper fibres ranged from 20.6 to $35.2 \%$ and $18.5-32.9 \%$ for 28 and 90 days of age, respectively. Reduction in the flexural strength of fibre cement specimens was $17.1-31.5 \%$ and $4.6-20.4 \%$ for 28 and 90 days of cured specimens, respectively. The observed decrease in compressive and flexural strength values of waste fibre cement composite is probably caused by formed air voids due to the incorporation of fibres into cement matrix and their mutual insufficient adhesion. This explanation of reduction of bond strength between fibres 
Table 2: Physical and mechanical properties of fibre cement composites and reference sample at 28 and 90 days of age

\begin{tabular}{|c|c|c|c|c|c|c|c|c|c|}
\hline \multirow[t]{2}{*}{ Waste paper fibre } & \multicolumn{3}{|c|}{ Density $\left[\mathrm{kg} / \mathrm{m}^{3}\right]$} & \multicolumn{3}{|c|}{$\begin{array}{c}\text { Compressive strength } \\
{[\mathrm{MPa}]}\end{array}$} & \multicolumn{3}{|c|}{$\begin{array}{c}\text { Flexural strength } \\
\text { [MPa] }\end{array}$} \\
\hline & $0.2 \%$ & $0.3 \%$ & $0.5 \%$ & $0.2 \%$ & $0.3 \%$ & $0.5 \%$ & $0.2 \%$ & $0.3 \%$ & $0.5 \%$ \\
\hline G-500T 28 & 2160.11 & 2143.41 & 2113.63 & 32.69 & 31.36 & 30.39 & 5.92 & 5.69 & 5.40 \\
\hline G-700T 28 & 2164.82 & 2144.51 & 2086.42 & 32.64 & 29.15 & 26.65 & 5.86 & 5.39 & 4.89 \\
\hline G-3/00T 28 & 2162.74 & 2128.58 & 2090.8 & 32.47 & 27.67 & 30.34 & 5.65 & 5.30 & 5.22 \\
\hline RF 28 & 2244.29 & & & 41.15 & & & 7.14 & & \\
\hline G-500T 90 & 2170.59 & 2127.35 & 2054.98 & 38.41 & 39.06 & 32.46 & 5.67 & 5.45 & 4.98 \\
\hline G-700T 90 & 2157.88 & 2121.51 & 2069.91 & 39.44 & 36.44 & 33.49 & 5.63 & 5.38 & 5.05 \\
\hline G-3/00T 90 & 2137.70 & 2102.93 & 2071.77 & 38.34 & 31.23 & 32.53 & 6.02 & 5.02 & 5.10 \\
\hline RF 90 & 2259.60 & & & 48.40 & & & 6.31 & & \\
\hline
\end{tabular}

and the matrix particles, leading to decrease in both mechanical strengths was presented in [23].

\section{Conclusions}

The three types of cellulosic fibres used in this experiment were obtained from recycled waste paper which were utilized into the cement mixture as a reinforcing agent. Physical and mechanical properties of fibre cement based composites were determined at 28 and 90 days of age and compared with reference sample. The increasing amount of cellulosic fibres up to $0.5 \%$ in composites caused the reduction in flowability of fresh cement mixtures as well as in density and compressive and flexural strength of 28 and 90 days of hardened composites. The highest strength parameters reached composites based on $0.2 \%$ cellulosic fibres after 28 and 90 days of hardening. Based on these strength values of fibre cement composites, these can be used as non-load bearing material or for plastering purposes.

Acknowledgement: The authors are grateful to the Slovak Grant Agency for financial support of the project VEGA 1/0277/15 and Project Institute of Clean Technologies for Mining and Utilization of Raw Materials for Energy Use. Reg. No. L01406.

\section{References}

[1] S. Das, S. Basak, M. Bhowmick, S.K. Chattopadhyay, M.G. Ambare, Waste paper as a cheap source of natural fibre to reinforce polyester resin in production of bio-composites, J. Polym. Eng., 2016, 36, 441-447
[2] S. Das, Mechanical and water swelling properties of waste paper reinforced unsaturated polyester composites, Constr. Build. Mater., 2017, 138, 469-478

[3] H.D. Dennis, A.J. Evans, A.J. Banner, P.J. Moore, Reducing the environmental footprint of concrete for ecoengineering marine structures, Ecol. Eng., 2017, DOI: /10.1016/j.ecoleng.2017.05.031

[4] C. Meyer, The greening of the concrete industry, Cem. Concr. Compos., 2009, 31, 601-605

[5] C.L. Hwang, V.A. Tran, J.W. Hong, Y.C. Hsieh, Effects of short coconut fiber on the mechanical properties, plastic cracking behavior, and impact resistance of cementitious composites, Constr. Build. Mater., 2016, 127, 984-992

[6] H. Gu, Tensile behaviours of the coir fiber and related composites after $\mathrm{NaOH}$ treatment, Mater. Design, 2009, 30, 3931-3934

[7] Ö. Andiç-Çakir, M. Sarikanat, H.B. Tüfekçi, C. Demirci, Ü.H. Erdoğan, Physical and mechanical properties of randomly oriented coir fiber-cementitious composites, Compos. Part B Eng., 2014, 61, 49-54

[8] R.D. Toledo Filho, K. Ghavami, G.L. England, K. Scrivener, Development of vegetable fibre-mortar composites of improved durability, Cem. Concr. Compos, 2003, 25, 185-196

[9] I. Merta, E.K. Tchegg, Fracture energy of natural fibre reinforced concrete, Constr. Build. Mater., 2013, 40, 991-997

[10] M. Khorami, E. Ganjian, Comparing flexural behaviour of Fibre - Cement Composites reinforced baggasse, wheat and eucalyptus', Constr. Build. Mater., 2011, 25, 3661-3667

[11] A. Sellami, M. Merzoud, S. Amziane, Improvement of mechanical properties of green concrete by treatment of the vegetals fibers, Constr. Build. Mater., 2013, 47, 1117-1124

[12] G.H.D. Tonoli, M.N. Belgacem, G. Siqueira, J. Bras, H. Savastano, F.R. Lahr, Processing and dimensional changes of cement based composites reinforced with surface-treated cellulose fibres, Cem. Concr. Compos., 2013, 37, 68-75

[13] G. Ramakrishna, T. Sundararajan, Impact strength of a few natural fibre reinforced cement mortar Cem. Concr. Compos., 2005, 27, 547-553

[14] V. Sangrutsamee, P. Srichandr, N. Poolthong, Re-pulped waste paper-based composite building materials with low thermal conductivity,, J. Asian Archit. Build., 2012, 11, 147-151

[15] L.H. Buruberri, M.P. Seabra, J.A. Labrincha, Preparation of clinker from paper pulp industry wastes, J. Hazard. Mater., 2015, $286,252-260$ 
[16] Y. Hamzeh, K.P. Ziabari, J. Torkaman, A. Ashori, M. Jafari, Study on the effects of white rice husk ash and fibrous materials additions on some properties of fiber-cement composites, J. Environ. Manage., 2013, 117, 263-267

[17] X. Xie, Z. Zhou, M. Jiang, X. Xu, Z. Wang, D. Hui, Cellulosic fibers from rice straw and bamboo used as reinforcement of cementbased composites for remarkably improving mechanical properties, Compos. Part B Eng., 2015, 78, 153-161

[18] STN EN 1015-3: 2000 Methods of test for mortar for masonry Part 3: Determination of consistence of fresh mortar (by flow table)

[19] STN EN 196-1: 2016 Methods of testing cement Part 1: Determination of strength

[20] S. Chakraborty, S.P. Kundu, A. Roy, R.K. Basak, B. Adhikari, S.B. Majumder, Improvement of the mechanical properties of jute fiber reinforced cement mortar: A statistical approach, Constr. Build. Mater., 2013, 38, 776-784
[21] C. Sawsen, K. Fouzia, B. Mohamed, G. Moussa, Effect of flax fibers treatments on the rheological and the mechanical behavior of a cement composite, Constr. Build. Mater., 2015, 79, 229235

[22] T. Ashour, H. Wieland, H. Georg, F.J. Bockisch, W. Wu, The influence of natural reinforcement fibres on insulation values of earth plaster for straw bale buildings, Mater. Design, 2010, 31, 4676-4685

[23] A.N. Raut, C.P. Gomez, Thermal and mechanical performance of oil palm fiber reinforced mortar utilizing palm oil fly ash as a complementary binder, Constr. Build. Mater., 2016, 126, 476483 